Journal of Development and Communication Studies, Vol. 5. No. 2, July 2017 - June 2018

ISSN (Online \& Print): 2305-7432.

http://www.devcomsjournalmw.org.

\title{
Knowledge, Attitude and Practice on Infant and Young Child Feeding: A Comparative Study of Radio Listening Club Members and Non-Members of Mudzi Wathu Community Radio in Mchinji District, Malawi
}

Frank B. Msiska, Beatrice Mtimuni, Oripah Kabambe, \& Japhet Ezra Mchakulu

Department of Human Nutrition Health, Lilongwe University of Agriculture and Natural Resources, Lilongwe, Malawi.Email:msiskafrank@gmail.com

\begin{abstract}
The current case-control study was conducted in Mchinji district in order to evaluate current infant and young child nutrition knowledge, attitudes, and practice (KAP) of radio listeners club (RLC) members and non-RLC members and also to determine if the frequency of listening to Mudzi Wathu Community Radio is directly related to improved knowledge, attitudes and perceptions (KAP) of RLC members. Further, the study examined whether or not community radio listeners club members were more knowledgeable in IYCF nutrition than non-RLC respondents with the purpose of assessing the effectiveness of disseminating nutrition information through mass media in general and through radio in particular and the benefits of having community radio listening clubs on improvement of KAP in communities.
\end{abstract}

Key words: Attitude, Knowledge, Practice, Radio, Radio Listening Club, community radio, Mudri Wathu https://dx.doi.org/10.4314/idcs.v5i2.2

(C) 2018. The Authors. This work is licensed under the Creative Commons Attribution 4.0 International License (CC-By-NC-ND). Users may freely share and redistribute this work provided that the author and the Journal of Development and Communication Studies are fully acknowledged. Users may not tweak or remix and offer this work for sale. The full license may be accessed at https:// creativecommons.org/licenses/by-nc-nd/4.0/ 


\section{Introduction}

\section{Situation Analysis of Malnutrition}

Malnutrition is a major contributing factor for child morbidity and mortality in developing countries (National Statistical Office [NSO], 2010). In Malawi, about 47\% of the under-five children are stunted in growth, whereas $4 \%$ and $13 \%$ are wasted and underweight, respectively (NSO, 2010). The prevalence of infant and under-five children mortality rate (per 1,000 live births) is remarkably high (which are 112 per 1000 live births). About $50 \%$ is due to malnutrition. Despite the several infant and young child nutrition programmes such as nutrition education and counselling, micronutrient supplementation, growth monitoring and promotion, promotion of breastfeeding through Baby Friendly Hospital Initiative (BFHI), prevention of acute malnutrition, maternal nutrition and the implementation of the essential nutrition actions, the problem of high child malnutrition places a significant challenge towards attainment of the Millennium Development Goals (MDG) on reduction of under-five and infant mortality rate in Malawi. Suboptimal breastfeeding contributes to about $19 \%$ of infant mortality rate (NSO, 2010). According to 2010 DHS, 63\% of children ages 6-59 months were anaemic. One in every four children (23\%) had mild anaemia, 36\% had moderate anaemia, and 3\% had severe anaemia. Anaemia prevalence was highest among children age 6-11 months (over 80\%), and decreased steadily with age between 12 and 59 months.

\section{Mass media and nutrition information dissemination}

The term mass media refers to any form of communication that simultaneously reaches a large number of people, including but not limited to radio, television, newspapers, magazines, the internet, billboards, films, recordings and books (Wilmer, 2006). Mass media in the form of radio broadcasts and programming are the primary sources of a wide variety of information including nutrition information for the general public.

Nutrition education is defined by the Society for Nutrition Education and Behaviour (2010), as any combination of educational strategies, accompanied by environmental support which is designed to facilitate voluntary adoption of food choices and other food and nutritionrelated behaviours. In addition, nutrition education, through multiple venues, involves activities at the individual, community, and policy levels. This now recognised as a primary form of intervention in national food and nutrition programmes. It is now viewed as an integral component of other nutrition intervention approaches since it can influence behaviour change. One example of education and communication activities include: the production and distribution of appropriate radio spots, jingles, documentaries, video and other audio materials. In general, the public obtains most of its nutrition and health information from a number of sources namely: the mass media in the form of radio, the professionals, family and friends (Turner, 1984). Mass media can thus influence health consciousness, knowledge, and attitudes that can cause behavioural and social change (Bridges, 2010). In addition, one of the most powerful aspects of the media (radio) is its ability to set the public's agenda. That is, media shapes what people view as important in the world, and it identifies and defines concerns, issues and problems. Community radio stations can play an advocacy role in creating awareness and attitude change (Upadhyay et al., 2011). In addition, according to the Australian National Health and Medical Research Council's Nutrition Education Report of 1989, radio reaches far more people in far less time, even though, single messages are unlikely to change strongly held attitudes and behaviours.

\section{Mudzi Wathu Community radio station}

Community radio stations is a valuable tool in facilitating and encouraging change and development by producing programs that are community focussed and relevant, addressing community specific issues and concerns (Waters et al., 2010). Local voices airing opinions about issues and generating community relevant solutions through dialogue is a key feature and purpose 
of community radio (Waters et al., 2010). Mudzi Wathu Community Radio Station (MWCR) which is facilitated by Mai Mwana Project was established for the rural areas of Mchinji district in Malawi. The station was established with a specific community-oriented focus to positively impact the social and health needs of the district with a population of approximately 115,000 people. In coordination with the District Health Office and the District Assembly, the station implements a wide variety of interventions addressing different maternal and child health and social needs. For example, the station broadcasts programmes on health issues such as hygiene, nutrition, the SUN movement, nutrition and HIV/ AIDS. Phukusi la Moyo program is facilitated by Mai Mwana Project, the District Health Office and the district assembly with funding from Commonwealth of Learning. In the case of Mudzi Wathu Community Radio, the themes and messages are developed in consultation with local health and nutrition authorities. The programmes are then recorded using professional talent. The programmes are then tested with representatives of the target audience before airing them, redrafted, and aired according to the listening habits of the target groups who are local listeners' club members.

\section{Membership of Mudzi Wathu Community Radio listeners clubs}

MWCR listeners' clubs are composed of women, mothers and caregivers of children under the age of five years adopted from the project name "Mai Mwana", which simply means "Mother and Child". Due to issues of male involvement, fathers of infants, chiefs and other local leaders are also included in these listeners clubs.

Various interventions are being implemented in Malawi which are aimed at promoting optimal infant, young child and maternal nutrition. These include implementation of the seven Essential Nutrition Actions (ENA): counselling and support, capacity building of health workers, training in academic institutions, group education and communication. However, nutrition indicators have not significantly improved over the years as shown in the Demographic and Health Survey (2010) results. For instance, in Mchinji district, 18.5\% of under-five children are severely stunted and $53 \%$ are moderately stunted, whereas $0.4 \%$ is severely wasted and $3.3 \%$ are moderately wasted. About 1.5\% and 13.1\% are reported to be severely and moderately underweight respectively (NSO, 2010). It is, therefore, apparent that there are some gaps and challenges in the way nutrition information reaches the audience.

Despite the involvement of the media in improving nutrition knowledge, little attention has been put in place to assess and evaluate how effective the media (Community radio) has been on its audience in terms of knowledge, attitude and practice in Mchinji district. Although "educational" program of this nature and other types are widespread and heard frequently, there has been little if any evaluation done on them. This current study assessed the effectiveness of delivering nutrition information through radio broadcasting by community radio stations using a knowledge, attitude and practice approach (KAP) in the case study of Mudzi Wathu Community Radio station in Mchinji district.

\section{Objectives and hypotheses of the study}

The study was aimed at assessing the knowledge, attitude and practice of RLC members on IYCF nutrition information disseminated by Mudzi Wathu Community Radio (MWCR). Specifically, it intended to: determine if the frequency of listening to MWCR is directly related to improved KAP of RLC members on IYCF information; assess the nutrition KAP on IYCF of RLC members of MWCR in Mchinji District; and compare KAP of RLC members and non-RLC members on optimal Infant and Young Child Feeding. The study hypothesised that: nnutrition Information disseminated by community radio on IYCF has positive effect on knowledge, attitude and practice of RLC members and that community radio RLC members are more knowledgeable in IYCF nutrition than their non-RLC members/counterparts. 


\section{Materials and Methods}

The study was conducted among RLC members and non-RLC members of Mudzi Wathu Community Radio (MWCR) of Mai Mwana project in the Mchinji. It covered the following four traditional authority areas: Zulu, Mduwa, Simphasi and Mavwere. Eligible participants for the study were RLC members and Non-RLC listeners of Mudzi Wathu Community Radio station who were either pregnant or lactating women or mothers of children who were less than five years of age $(0-$ 59 months). Women who took part in the pre-testing of the questionnaire and those who did not give consent were automatically excluded from the study. The women who took part in the pretesting fitted into the targeted sample as they were selected amongst the radio listener club members. These were finally and deliberately excluded from the selected sample during actual data collection to avoid and minimize bias and duplication of efforts.

A multi-stage sampling technique was used for selection of study units. Mchinji district was purposively selected because of the presence of an operational community radio station, then purposive sampling of four traditional authorities with full coverage of Mudzi Wathu Community Radio, and random selection of listeners clubs within the TA. This was then followed by systematic selection of households belonging to RLC members. Using snow-balling technique each randomly selected RLC member was requested to identify one non-RLC listener resident in the same community who in turn was treated as a control.

The sample size was originally arrived at using the general formula for calculation of sample size; $\left[\mathrm{N}=2\left\{\mathrm{t}^{2}(\mathrm{pxq}) / \mathrm{d}^{2}\right\}\right]$. This gave a sample size of 192.08 which was rounded up to 200 participants. Only four of these traditional authority areas under study have one hundred percent coverage from the MWCR. These TAs were then purposively selected. A total of 129 radio listeners clubs were listed down in these four TAs. Through systematic random sampling, 25 RLCs in each of the selected four TAs was randomly selected. Each club could register on average 25 RLC members who were, by default, women, mothers and caregivers of children under the age of 5 years. In case of inadequate numbers of RL Clubs per TA, replacements were done by randomly selecting for the remaining clubs. Using a sampling interval of five, five RLC members were randomly selected in each of the $25 \mathrm{RL}$ Clubs per TA. This procedure resulted in a sample size of 25 RLC members per TA. Consequently, a sample size 100 RLC members was selected. The same sample size of 100 was achieved for Non RLC members using snow balling technique. After data collection and entry only 97 questionnaires for RLC members and 100 for non-members were found to be valid.

Data collection was accomplished using interviewer administered questionnaires designed to obtain relevant socio-demographic characteristics, knowledge, attitude and practice towards infant and young child nutrition. The questionnaire was developed by the principal researcher based on common IYCF parameters for assessment of KAP which included early initiation of breastfeeding, exclusive breastfeeding, optimal complementary feeding and infant feeding in the context of HIV and AIDS. In addition to KAP, exposure to radio and listening frequencies data were collected. This was done to compare and relate radio listening to KAP on IYCF. The survey questionnaire was administered by trained local enumerators. The survey team composed of five enumerators and one supervisor who travelled to selected villages. Eligible women were informed in advance on the survey dates. Data collection was completed in 10 days during the period from the second week to the last week of November 2013. Two sets of information were analyzed in this survey. These were: data on nutrition information disseminated by the Mudzi Wathu Community Radio on IYCF and infant and young child feeding knowledge, attitude and practices for children 0-59 months. The two sets of information were inclusive and interlinked. Data were re-coded into the relevant indices as described in the definitions of indicators for IYCF (WHO indicators).

Data analysis was done using the SPSS Software Version 16.0. In cases of possible multiple correct answers, respondents were asked to mention only one of the expected list of correct/wrong answers that they deemed very important to them. Each respondent was then analysed according 
to the same, on the questions related to knowledge, attitude and practice related to nutrition information disseminated by Mudzi Wathu Community Radio. Data on KAP was entered in Excel then exported to SPSS where computation for different indices was done to categorise the subjects and comparison between groups. Frequencies and cross tabulation were run on the data according to the groups to which the participants belonged. Cross tabulation and independent samples test were computed to compare the two groups on categorical parameters and test for significance at $95 \%$ CI.

\section{Results and discussions}

\section{Demographic characteristics}

Of the 197 community dwelling pregnant and lactating women who participated in this study, information about age of spouse was available representing $100 \%$, and age of household head (males) was available only on 167 respondents representing 85\%. Information on household size was available for only 194 respondents which represented $99.5 \%$ of the respondents. The mean age of female spouses who were RLC members at the time of the study was $32.07 \pm 7.5$ years and $38.05 \pm 8.1$ years for the household heads. All respondents in the study were women. Average ages for non-RLC listeners female spouses were 28.42 \pm 7.5 years and $34.05 \pm 8.9$ years for the male heads of the household respectively. All the households sampled in this current study were male headed. The distribution shows that the younger age group make up the higher proportion of household population in rural areas. This is in line with the national statistics in the MDHS (2010), where $67 \%$ of the total population is under the age of 25 while $4 \%$ of the population are aged 65 or older. The mean household size for RLC listeners was $5.4 \pm 1.7$ members and $5.1 \pm 1.8$ for non-RLC members. This is also consistent with the national statistics, whereby the average household size for the rural areas is 4.7 persons having slightly more members than the urban areas (NSO, 2010). Socio-demographic characteristics of study participants and their households

\begin{tabular}{lccc}
\hline Parameter & $\begin{array}{c}\text { RLC members } \\
(\mathbf{n = 9 2})\end{array}$ & $\begin{array}{c}\text { Non-RLC } \\
\text { members } \\
(\mathbf{n = 1 0 3})\end{array}$ & P-value \\
\hline Mean age of household head (years) & $38.05 \pm 8.1$ & $34.05 \pm 8.9$ & .058 \\
Mean age of spouse (years) & $32.07 \pm 7.5$ & $28.42 \pm 7.5$ & .193 \\
Mean household size & $5.4 \pm 1.7$ & $5.1 \pm 1.8$ & .263 \\
Marital status (\%) & 89.1 & & \\
Married & 3.3 & 90.8 & .550 \\
Widowed & 3.3 & 2.6 & .550 \\
Separated & 1.1 & 2.1 & .550 \\
Cohabiting & 3.3 & & .550 \\
Never married & & 4.9 & .550 \\
Major source of income (\%) & 90.2 & & \\
Farming & 5.4 & 89.2 & .550 \\
Self-employed & 3.3 & 8.7 & .550 \\
Causal labour & 1.1 & 2.9 & .550 \\
Petty trade & & & \\
Educational status (\%) & & & \\
Household head & 24.1 & 5.3 & .550 \\
None & 55.7 & 78.9 & .550 \\
Primary school level & 20.3 & 15.8 & .550 \\
Secondary school level & & & .550 \\
Spouse & 7.6 & 12.6 & \\
None & &
\end{tabular}




\begin{tabular}{lccc}
\hline Primary school level & 77.2 & 71.8 & .550 \\
Secondary school level & 15.2 & 15.4 & .550 \\
\hline
\end{tabular}

There were no significant differences in almost all the socio-demographic characteristics between the radio listening club members and those of non-RLC members. For instance, $89.1 \%$ of the RLC members and $92.2 \%$ of the non-RLC members were married $(p=0.550)$ etc.

\section{Exposure to radio and behaviour change}

There was evidence of changes in infant feeding behaviours by people in the communities directly as a result of broadcasts as about $94 \%$ of the RLC members and $94.1 \%$ of the non-RLC members agreed about the feeling of change in behaviour. All the RLC members, and about $93.1 \%$ of the non-RLC members, in their understanding agreed with the fact that sharing of nutrition information on a community radio increases awareness and knowledge, attitude and practice in infant and young child nutrition. There were significant differences between RLC members and non-RLC members in terms of proportion of respondents who suggested actual change in behaviour after listening to broadcast $(\mathrm{p}<0.001)$ and the proportion who suggested that information sharing on community radio increases knowledge and improves attitude and practice $(\mathrm{p}=0.022)$. This is in line with the findings of a study done in Philippines and Nicaragua by Cooke and Romweber (1997) where the results showed increased positive knowledge and attitude toward putting oil to rice porridge increased from $15 \%$ at the baseline to $74 \%$ after one year of broadcast.

\section{Radio listening habits}

The results suggested that $94.6 \%$ of the RLC members have used the information whereas about $52 \%$ of the non-RLC members indicated that they had used the information disseminated and almost half of them (47.5\%) had never used it. Around $40 \%$ of RLC members who had never used the information indicated that they are 'very likely' to use it, $40.0 \%$ were only 'likely' to use the information; about $20 \%$ would 'possibly' use the information. Similarly, less than half $(42.3 \%)$ of the non-listener were 'very likely' to use it, $30.8 \%$ were just 'likely' going to use it, about $11 \%$ indicated that they were 'possibly' going to use it and 15.4\% were 'unlikely' going to use the nutrition information being disseminated by Mudzi Wathu Community Radio. There was a significant difference between the RLC members and non-RLC members in terms of proportion of participants who ever used the information disseminated by MWCR $(p<0.001)$ which indicate that more RLC members have used the information than the non-RLC members.

\begin{tabular}{|c|c|c|c|c|c|}
\hline \multirow[t]{2}{*}{ Parameter } & \multicolumn{2}{|c|}{$\begin{array}{c}\text { RLC } \\
\text { members }\end{array}$} & \multicolumn{2}{|c|}{$\begin{array}{c}\text { Non-RLC } \\
\text { members }\end{array}$} & \multirow[b]{2}{*}{ p-value } \\
\hline & $\mathbf{n}$ & $\%$ & $\mathbf{n}$ & $\%$ & \\
\hline $\begin{array}{l}\text { Proportion of participants who } \\
\text { ever used information } \\
\text { disseminated by MWCR. }\end{array}$ & 87 & 94.6 & 5 & 5.4 & .000 \\
\hline $\begin{array}{l}\text { Proportion of participants very } \\
\text { likely to use the information } \\
\text { disseminated by MWCR. }\end{array}$ & 2 & 40 & 11 & 42.3 & .773 \\
\hline $\begin{array}{l}\text { Proportion of participant likely to } \\
\text { use the information. }\end{array}$ & 2 & 40 & 8 & 30.8 & \\
\hline $\begin{array}{l}\text { Proportion that were possibly to } \\
\text { use the information. }\end{array}$ & 1 & 20 & 11 & 3 & \\
\hline $\begin{array}{l}\text { Proportion that were unlikely to } \\
\text { use the information. }\end{array}$ & & & 4 & 15.4 & \\
\hline
\end{tabular}




\begin{tabular}{llllll}
\hline $\begin{array}{l}\text { Proportion of respondents } \\
\text { indicating that information on }\end{array}$ & & 95.7 & 89 & 88.1 & .058 \\
$\begin{array}{l}\text { IYCF was available to them. } \\
\begin{array}{l}\text { Proportion indicating that } \\
\text { MWCR was their first source of }\end{array}\end{array}$ & 40 & 43.5 & 15 & 14.9 & .000 \\
information \\
$\begin{array}{l}\text { Proportion indicating that Health } \\
\text { Worker was their first source of }\end{array}$
\end{tabular}

\section{Relationship between participants' knowledge and attitude and the frequency of listening to MWCR broadcasts}

The results of this study shows that the RLC members who had a habit of listening "twice a week" were more knowledgeable and had more positive attitudes than those who listened less. In the case of the listeners, there was significant relationship between the frequency of listening to the MWCR's Phukusi la Moyo programme and the source of information about exclusive breastfeeding $(\mathrm{p}<0.001)$. The majority of the respondents $48.4 \%$ listened to the radio twice a week. In addition, more than half $68.4 \%$ who listened to the programme as scheduled felt that they were very well informed about exclusive breast-feeding $(\mathrm{p}<0.001)$ and that they felt that they were quite knowledgeable about the benefits and advantages of exclusive breastfeeding over infant formulae $(\mathrm{p}=0.02)$.

According to these results, frequency of listening to the broadcast was also directly related to the following categorical variables: knowledge about early initiation of breast-feeding $(\mathrm{p}=$ 0.015), the negative effects of pacifiers $(\mathrm{p}=0.01)$, knowledge of whether HIV positive mothers can infect their infants with HIV $(\mathrm{p}=0.01)$ and the importance of HIV testing during pregnancy $(p=0.01)$. Regarding knowledge about the Malawi Six Food groups among the listeners, the results suggest that there was positive correlation between the frequency of listening to Phukusi la Moyo programme and the number of groups that the RLC members were able to mention $(p=0.01)$. In addition, those who listened twice, as scheduled, were able to mention the signs of malnutrition as wasting, stunting and underweight $(\mathrm{p}=0.006)$ as compared to those who listened less frequently. Similarly, those who listened regularly to the MWCR broadcast considered optimal infant and young child feeding as essential for growth and development of the child $(p=0.03)$.

\section{Types of nutrition information disseminated by Mudzi Wathu Community Radio}

After coding and running through content analysis of frequencies using SPSS, the study revealed that almost two thirds $(72.7 \%)$ of the different programmes broadcast on MWCR mentioned the themes and subthemes related to optimal infant and young child feeding according to WHO recommended indicators. For example, the findings indicate that a total of nine programmes mentioned issues on duration of exclusive breastfeeding representing $81.1 \%$. These themes included: exclusive breast-feeding, optimal complementary feeding, nutrition and HIV and the Malawi six food groups. These themes were further divided into subthemes. There were a total of 11 programmes that were purposively selected depending on their relevance to the objectives of the study.

\section{KAP on Infant and young child feeding}

In this study, most of the participants had good knowledge of breast-feeding. A large proportion of participants agreed that breastfeeding is an optimal way of feeding the infants. The results also indicated that nearly all participants (100\%), regardless of listening code have heard and are aware of exclusive breastfeeding. A greater proportion (71.7\%) of RLC members indicated that they heard about exclusive breastfeeding (EBF) from a Mudzi Wathu Community Radio as compared to only $17.5 \%$ of the non-RLC members. Less than half $(28.3 \%)$ of RLC members had heard about 
EBF from a health worker while a majority of non-listeners, $81.6 \%$ indicated that they heard it from health workers. However, a greater proportion of the RLC members $(96.7 \%)$ were able to state that children need to be exclusively breastfed for 6 months as well as $92.2 \%$ of the non-RLC members Similarly, $89.1 \%$ of the RLC members indicated continued breastfeeding up to two years and beyond as compared to $93.2 \%$ of the non-RLC members. Sixty three percent of the RLC members were able to state the benefits of EBF as cheap, 19.6\% mentioned "immunological factors", and 13\% mentioned "right temperature" for the baby. Further 2.2\% said EBF promotes bonding between the mother and the child. Similarly, 67\% of the non-RLC members mentioned cheap, $10.7 \%$ stated that it has immunological values, $13.6 \%$ indicated that it has the right temperature and $2.9 \%$ suggested that EBF promotes bonding between the mother and the child. The results showed no significant differences between the two comparison groups $(p=0.356$ Participants knowledge about early initiation and benefits of EBF

\begin{tabular}{|c|c|c|c|c|c|}
\hline \multirow[b]{2}{*}{ Parameter } & \multicolumn{2}{|c|}{$\begin{array}{c}\text { RLC } \\
\text { members }\end{array}$} & \multicolumn{2}{|c|}{$\begin{array}{l}\text { Non-RLC } \\
\text { members }\end{array}$} & \multirow[b]{2}{*}{ p-value } \\
\hline & $\mathbf{N}$ & $\%$ & $\mathbf{n}$ & $\%$ & \\
\hline \multicolumn{6}{|c|}{ Proportion of participants able to mention benefits of EBF (\%) } \\
\hline Cheap & 58 & 63.0 & 69 & 67.0 & .356 \\
\hline Has immunological factors & 18 & 19.6 & 11 & 10.7 & \\
\hline Right temperature & 12 & 13.0 & 14 & 13.6 & \\
\hline Promotes bonding & 2 & 2.2 & 3 & 2.9 & \\
\hline \multicolumn{6}{|c|}{$\begin{array}{l}\text { Proportion of participants able to mention correct time for Early initiation of } \\
\text { EBF (\%) }\end{array}$} \\
\hline Immediately after birth & 70 & 76.1 & 86 & 83.5 & .294 \\
\hline After one hour & 21 & 28.8 & 17 & 16.5 & \\
\hline \multicolumn{6}{|c|}{ Proportion of participants correctly mention the negative effect of pacifiers $(\%)$} \\
\hline Respiratory tract infections & 18 & 19.6 & 26 & 25.5 & .599 \\
\hline Diarrhoeal & 51 & 55.4 & 51 & 50.0 & \\
\hline \multicolumn{6}{|c|}{ Proportion of participants who stated that colostrums is good for child health } \\
\hline Is colostrum good for child health & 90 & 97.8 & 102 & 99.0 & \\
\hline
\end{tabular}

Infant and young child feeding in the context of $\mathrm{HIV}$

According to the results of the current study, $87 \%$ of the RLC members had the opinion that HIV positive mothers should exclusively breastfeed their infants, as compared to $79.6 \%$ of the nonlisteners. About $32.6 \%$ of the RLC members suggested that HIV positive mothers can infect their infants during breastfeeding as compared to $30.1 \%$ of non-RLC members group. More than half of both RLC members (66.3\%) and non-RLC listeners (66.0\%) indicated that they cannot infect their children with the HIV virus. Although more RLC members indicated that HIV positive mothers should exclusively breastfeed their infants and that breastfeeding can infect the child with HIV than the non-RLC listeners, the difference was not significant $(p=0.388)$ and $(p=0.454)$ respectively. All the RLC members were aware of the fact that it is important for pregnant mothers to test for HIV during pregnancy as compared to $97.4 \%$ of the non-listeners. However, there was a significant difference among the two groups in terms of proportion of mothers who suggested that it is not important for HIV testing during pregnancy $(\mathrm{p}=0.032)$. More of the non-RLC members indicated that it is not important to test.

\section{Knowledge about the Malawi Six Food groups}

The two groups did not significantly differ on whether they recall any of the Malawi six food groups ( $\mathrm{p}=0.604$ ), $92.4 \%$ of the RLC members and $90.3 \%$ of the non-RLC members were aware of the Malawi six food groups. However, the two groups differed significantly $(p<0.001)$ in terms 
of the number of groups that they were able to mention. About $73 \%$ of RLC members and $40.9 \%$ of the non-RLC members, who responded that they were aware of the Malawi six food groups, could mention four to six food groups respectively, and only $12.5 \%$ and $46.9 \%$ were able to mention only three food groups.

\section{Community encouragement of breastfeeding and breastfeeding in public}

Of the listening group, $91.3 \%$ indicated that the community allows for $\mathrm{BF}$ as compared to those RLC members 3.3\% who responded that they are not encouraged to BF. About $94.1 \%$ of nonRLC members suggested that the community encouraged breastfeeding as compared to only about $4 . \%(n=4)$ who suggested otherwise, almost $5.4 \%$ and $2 . \%$ of RLC members and non-RLC members respectively indicated that their community somehow encouraged breastfeeding. However, $100 \%$ and $98.0 \%$ of both RLC members and non-RLC members respectively suggested that mothers could breastfeed in public. Furthermore, $98.9 \%$ of the RLC members and all the non-RLC members suggested that it is in order for mothers to breastfeed in public.

\begin{tabular}{lllllll} 
Participants' attitude and perception of malnutrition \\
\hline Parameter & $\begin{array}{l}\text { RLC } \\
\text { members }\end{array}$ & $\begin{array}{l}\text { Non-RLC } \\
\text { members }\end{array}$ & \\
\hline & $\mathbf{n}$ & $\mathbf{\%}$ & $\mathbf{n}$ & $\mathbf{\%}$ & p- value \\
& $\begin{array}{l}\text { Proportion of participants who suggested } \\
\text { someone with malnutrition as "outcast" }\end{array}$ & 6 & 6.5 & 0 & 0 & .069 \\
$\begin{array}{l}\text { Proportion of participants who suggested } \\
\text { someone with malnutrition as "bewitched" }\end{array}$ & 0 & 0 & 2 & 2 & .069 \\
$\begin{array}{l}\text { Proportion of participants who suggested } \\
\text { someone with malnutrition as "caretaker } \\
\text { careless" }\end{array}$ & 39 & 42.4 & 48 & 47.5 & .069 \\
$\begin{array}{l}\text { Proportion of participants who suggested } \\
\text { someone with malnutrition as "poor" }\end{array}$ & 35 & 38.5 & 38 & 37.6 & .069 \\
\hline
\end{tabular}

An independent samples t-test was conducted to examine whether there was a significant differences between RLC members and non-RLC members in relation to knowledge, attitude and practice. The test revealed no statistically significant difference in all the measured variables except a noticeable statistically significant difference in relation to knowledge of sources of water during breast feeding $(\mathrm{p}=0.022)$. RLC members reported lower levels of knowledge than did the nonRLC members. In addition there was statistically significant difference in relation to knowledge about the importance of HIV testing before giving birth (Table 4.17). The test revealed statistical difference between RLC members and non-RLC members $(p=0.025)$ though the difference was small.

On knowledge about the six food groups, the test showed a statistically significant difference $(p=0.001)$, RLC members showed higher levels of knowledge on the Malawi six food groups than non-RLC members. On initiation of solid foods, after exclusive breast feeding, the test revealed a significant difference between the two groups. Those who were non-RLC members showed higher levels of knowledge about when to introduce solid foods which is after six months than RLC members.

On behaviour change and practice, the test showed statistically significant difference in terms of change of practice after listening to broadcast on EBF on the community radio $(\mathrm{p}=$ 0.001). There was statistically significant difference in terms of participants understanding of the fact that sharing information on nutrition on a community radio increases awareness and knowledge $(\mathrm{p}<0.05)$. Non RLC members show more positive faith in the ability of the radio station than the RLC members and this could be due to the fact that they (non-RLC listeners) felt that they were less well informed about IYCF information than the RLC members. The type of 
infant and young child feeding was not affected by the socio-economic/socio-demographic status of the families, including their education level, occupation and monthly income of mothers, fathers and caregivers. The highest percentages of mothers were housewives and mothers' occupation had no significant relation with mother's knowledge, attitudes and practices.

\section{Conclusion}

The results of survey study suggest that most of the study respondents were illiterate or primary school leavers and house wives. The men were unskilled labourers and majority of mothers and fathers were farmers. Majority of surveyed infant and young child's feeding pattern knowledge was exclusive breast feeding, and optimal complementary feeding. Mothers surveyed had sufficient knowledge and positive attitude and practice of infant and young child feeding. Targeting family members throughout the implementation of educational activities and media campaigns is a need identified by this study for improving the outcome of the Infant and Young Child Feeding on community practices.

In summary, the following are the conclusions from the study: a larger proportion of the respondents knew about optimal infant and young child feeding; the study also found that the community judged the local community radio station to have made a significant change in community life. According to the RLC members it is clear that the broadcasts made a positive impact on the quality of life of the people who live in Mchinji district through a combination of strategically designed on and off-air activities based on a community development and participation approach to radio programming; mass media plays an important role in the mothers' lives and represents an important source of information that influence mothers' practices and hence child health. When used in a culturally effective manner it becomes a vitally important educational tool for reaching out to mothers of different needs and socioeconomic levels in the society; it is clear that more mothers and caregivers in Mchinji district are knowledgeable about the hazards of baby bottles and use of pacifiers and they prefer to soothe and comfort their babies by carrying them rather than to give them nipples or teats. These mothers may receive more pressure from their social network to offer their babies teats and nipples, with no knowledge about their negative effect on breastfeeding and without teachings regarding alternative ways to soothing their babies.

It is clear also that health staff and media campaigns need to focus on raising awareness of young and first time mothers and their family members about the hazards of nipples and teats. The frequency of listening to MWCR was found to directly correlate to improve KAP on IYCF nutrition amongst RLC members. Although there appeared to be significant contribution of the community radio on knowledge, attitude and practice amongst the RLC members, the final results of the study clearly indicates that there were no statistically significant differences between the RLC members and the non-RLC members on knowledge, attitude and practice between the two studied groups. 


\section{References}

Abul-Fadi, A.T. (2012). Evaluation of Mothers Knowledge, Attitude and Practice Towards Ten Steps to Successfull Breastfeeding in Egypt. British Medical Journal 7(3): 173-178. DIO:10.1089/bfm.2011.0028.

Bridges, N. (2010). Breastfeeding In the Australian Media. Public Communication Review, 1:5764.Available http://epress.lib.uts.edu.au/journals/index.php/pcr/article/view/1409/1525 [Accessed on 15 January 2015].

Cookie, T. (1977). Radio, Advertising Techenique and Nutrition Education; A summary of field experiment in the phillipnes and Nicaragua. Washington DC. Mannoff Internationa Inc. Available at http://manoffgroup.com/documents/RadioEducationProjectFinalReport.pdf. [Accessed on 22 April 2015].

Escalada, M., K. (2004). A Case of Using Mass Media; Communication and behaviour change in resource management.Metro Manilla, Phillipines. International Rice Research Institute. Available at http://www.cropscience.org.au/icsc2004/pdf/356 escaladam.pdf [Accessed on 22 April 2015].

Faxal, S. (2013). Infant and Young Child Feeding Knowledge, Attitude and Practices assessment. Dadu District. Sindhi Province. Pakistan. Annals of Medical and Health Sciences Research, 3(3): 370375. DOI:10.4103/2141-9248.117955.

Food and Agriculture Organisation of the United Nation (2007). Somali Knowledge, Attitude and Practice study; Infant and Young Child Feeding and health seeking practice. Food Security Analysis Unit. Mogadishu, Somalia. Available at https://ethnomed.org/clinical/pediatrics/somali knowledge attitude practices study d ec07.pdf/view [Accessed on 19 May 2016].

Foss, K. (2006). Infant Feeding and the Media; The relationship between parents's magazine content and breastfeeding. International Journal of Breastfeeeding, 1:10.DOI:10.1186/17464358-1-10.

Henderson, L. (2000). Representing Infant Feeding; Content analysis of British Media portrayals of Bottle feeding and Breastfeeding. British Medical Journal, 321:1196-1198. DIO:10.1136/bmj.321.7270.1196.

Kirsi, T. (2011). Child Nutrition Communication for Small Children in Egypt. Cairo.Egypt. Available at: http://www.diva-portal.se/smash/get/diva2:396995/FULLTEXT02.pdf [Accessed on 20 April 2016].

Kuzima, J. (2013). Knowledge, Attitude and Practice related to Infant Feeding Among Women in Rural Papua New Guinea; A descriptive, mixed method study. International Journal of Breastfeeding 8: 16. DOI: 10.1186/1746-4358-8-16.

Magawa, R. (2013). Knowledge, Attitude and Practice Regarding Exclusive Breastfeeding in Southern Africa, Part 1. South Africa. Available at: http://www.polity.org.za/article/knowledge-attitudesand-practices-regarding-exclusive-breastfeeding-in-southern-africa---part-1-2012-12-05 [Accessed on 15 July 2015].

Matta, C. (2011). Radio drama, a pilot project for nutritional health communication in Inuit communities. School for dietetics and Human Nutrition. McGill University. Montreal Q.C, Canada. Thesis Available at: http://digitool.library.mcgill.ca/R/-?func=dbin-jumpfull\&object_id=104792\&silo_library=GEN01 [Accessed on 18 January 2016].

Ministry of Health . (2008). Infant and Young Child Feeding Policy. Lilongwe, Malawi: Ministry of Health .

Mohammed, K., Khader, Y., Amirin, Z. and Alkadajel, A. (2006). Knowledge, Attitude and Practice of Breastfeeding in the North of Jordan; A cross sectional study. International Breastfeeding Journal, 1:17. DOI:10.1186/1746-4358-1-17. 
Munger, S.J. (1978). Mass Media and Non-formal Nutrition Education: Final study report. Agency for International Development, US Department of State. Available at: http://pdf.usaid.gov/pdf_docs/PNAAP405.pdf [Accessed on 18 July 2015].

Nazari, R. and Hasbullah, A. (2010). Radio as an Educational Media; Impact on agriculture development. South, East Asia research centre for communication and humanities. Available at: https://www.researchgate.net/publication/258517524_Radio_as_an_Educational_Media _Impact_on_Agricultural_Development [Accessed on 19 May 2016].

National Statistical Office and ORC Macro (2005). Malawi Demographic and Health Surveys 2004. Zomba, Malawi and Calverton, Maryland: NSO and ORC Macro.

National Statistical Office and ORC Macro (2010). Malawi Demographic and Health Surveys 2008. Calverton, Maryland: NSO and ORC Macro.

National Institute of Agricultural Extension Managemenet (2010). Communication and Diffussion of Agricultural Innovations. Andhra Pradesha,India: Rajendranagar.

Romero-Gwynn, E. and Marshall, M.K. (1990). Radio: Untapped Teaching Tool.Journal of Extension, 28(1).

Shah, P. (2010). Improvement of Nutrition Related Knowledge and Behaviour of Urban Asian Indian School Children: Findings from medical evaluation for children/adolescents for realistic prevention of obesity and diabetis and for healthy aging intervention study. British Journal of .Nutrition, 104: 427-236.DOI: 10.1017/S0007114510000681

Shaker, Z. A.,Hussein, K,A. and Al-Azzawi, S. (2009). Knowledge, Attitude and Practice of Mothers Towards Infant and Young Child Feeding in Primary Health Care Centres, Ebrbil city. Iraqi Academic Scientific Journal, 2(2): 118-126.

Shiratori, S. (2011). Impact of Nutrition Information of Consumers Food Purchases. PhD thesis, University of Minnesota.Available at: http://hdl.handle.net/11299/116323 [Accessed on 28 June 2015].

Sommerlad, E.A., Robin, A. (1997). Health Alliance and Social Action Broadcasting; Assessment of local radio project. Journal of Health Education, 56:51-63.DOI: $10.1177 / 001789699705600106$.

Tan, K. (2009). Knowledge ,Attitude and Practice on Breastfeeding in Klang, Malaysia. The International Medical Journal of Malaysia. 8(1):17-22.

Tomasoni, L. (2011). Knowledge, Attitude and Practice Regarding Newborn Feeding Modalities in HIV-infected and HIV-uninfected Women in Sub Saharan Africa: A multi-centre study. Journal of International Health. 3:56-65.DOI: 10,1016/j.inhe.2010.11.004.

Turner, M. (1984). The Mass Mass Media and Other Channels for Nutrition Information. Proceedings of the Nutrition Society, 41(2):211-216. DOI: 10.1079/PNS19840045.

United Nations Children's Fund (2012). Infant and Young Child Feeding Programming Status, Results of 2010-2011 Assessment for Key Actions for Comprehensive Infant and Young Child Feeding programme in 65 Countries Report. UNICEF, Accra, Ghana. Available at: https://www.unicef.org/IYCF_65_country_assessment_report_UNICEF.pdf [Accessed on 27 November 2015].

United Nations Children Emergency Fund (2012). UNICEF Annual Report. UNICEF, New York. 95-07/20. Available at: https://www.unicef.org/publication/index 69639.html. [Accessed on 8 June 2015].

United Nations Children Emergency Fund (2014). Annual Results Report (Nutrition).UNICEF/NYHQ2012-0156.Available http://www.unicef.org/publication/index 82455.html. [Accessed on 7 June 2015].

United Nations Children Emergency Fund (2010). Infant and Young Child Feeding Programme Guide. Nutrition Section Programmes. UNICEF, New York. Available at: https://www.unicef.org/nutrition/files/final IYCF. [Accessed on 30 July 2015].

Upadhyay, A. (2011). Media Accessibility and Preference for Food and Nutritional Information by Rural Women of India. Journal of Communication, 2(1): 33-40. 
Waters, D., James, R. and Darby, J. (2011).Health Promoting Community Radio in Rural Bali; An impact evaluation. Rural and Remote Health 11:1555. Available at: https://www.ncbi.nlm.nih.gov/pubmed/21375357 [Accessed on 12 February 2016].

Wimmer, R. (2006). Mass Media Research: An introduction, $8^{\text {th }}$ ed. California: Thompson Higher Education.

World Health Organisation (2014). Infant and Young Child Feeding Fact Sheet. WHO Press, Geneva. Switzerland. Available at: http://www.who.int/mediacentre/factsheets/fs342/en/ [Accessed on 20 October 2015].

World Health Organisation (2010). Guidelines on HIV and Infant feeding 2010: Principles and recommendations for infant feeding in the context of HIV and a summary of evidence. Geneva, Switzerland. Available at: http://www.who.int/maternal_child_adolescent/documents/9789241599535/en/ [Accessed on 11 September 2015].

World Health Organisation (2009). Infant and Young Child Feeding; Model Chapter for textbooks for medical students and allied health professionals. Geneva, Switzerland. Available at: http://www.who.int/maternal_child_adolescent/documents/9789241597494/en/ [Accessed on 28 August 2015].

Wright J., Romero-Gwynn E., Cotter A., Powell C., Garrett C., Grajales-Hall M., Parnell S., Stanford G., Wightman N., Williams E. (1996).Radio is effective in teaching nutrition to Latino families. California Agriculture. Available at: https://ucanr.edu/repositoryfiles/ca5006p1469795.Radio_is_effective_in_teaching_nutrition_to__Latino_families [Accessed on 20 May 2016]. 